DOI: $10.17805 /$ zpu.2015.4.10

\title{
Функции экологической культуры: анализ определений
}

\author{
A. А. ФОРТУНАТОВ \\ (МОСКОВСКИЙ ГУМАНИТАРНЫЙ УНИВЕРСИТЕТ)
}

Признание важности формирования экологической культуры, активное обращение научного знания к этой проблеме еще не привели к раскрытию ее теоретико-методологических основ. Внимание исследователей оказалось сосредоточенным преимущественно на таких острых вопросах, как разрушение экологической культуры и последствия этого: загрязнение среды, истощение ресурсов и т. д. Эти жизненно важные для общества вопросы нередко рассматриваются без использования соответствующей научной методологии. Однако постепенно возникло осознание необходимости создания концептуальной базы для изучения проблем формирования экологической культуры.

В статье на основе анализа работ ряда российских ученых были выделены следующие функции экологической культуры: ценностная, регулятивная, передачи социального опыта, диалоговая и знаковая. Также дефиниции экологической культуры были разделены на описательные, исторические, ценностные, психологические, структурные и культурологические определения. На основании выделенных критериев анализируются определения экологической культуры исходя из полноты представленности в них культурных функций.

Отмечается, что общим признаком приведенного анализа дефиниций является наличие в них человека и его деятельности как смыслообразующего начала. Данный анализ способствует более глубокому пониманию определений экологической культуры, а также наличию в них тех или иных составляющих.

Ключевые слова: функции культуры; экологическая культура; функции экологической культуры

\section{ВВЕАЕНИЕ}

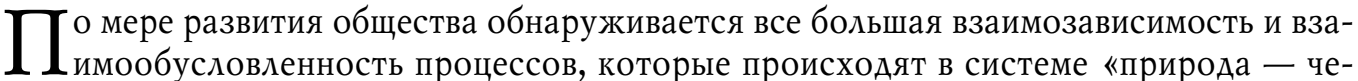
ловек - общество». Экологическая ситуация, сложившаяся в настоящее время, вывела на передний план проблемы взаимодействия общества и природы, остро поставив вопрос о формировании экологической культуры и выявлении ее роли в оптимизации социоприродного взаимодействия.

Признание важности формирования экологической культуры, активное обращение научного знания к этой проблеме еще не привели к раскрытию ее теоретико-методологических основ. Внимание исследователей оказалось сосредоточенным преимущественно на таких острых вопросах, как разрушение экологической культуры и последствия этого: загрязнение среды, истощение ресурсов и т. А. Эти жизненно важные для общества вопросы нередко рассматриваются без использования соответствующей научной методологии. Однако постепенно возникло осознание необходимости создания концептуальной базы для изучения проблем формирования экологической культуры. 
Исследования экологической проблемы однозначно подтверждают ее глубокую связь с сущностью человека, особенностями его культуры. Без анализа культуры, ее развития в принципе невозможно выяснить подлинные механизмы решения экологической проблемы. Культурологические и экологические исследования, таким образом, пересекаются, доказывая единство человека, общества и природы.

В настоящее время единого общепринятого определения экологической культуры не существует. Это, видимо, связано с тем, что нет однозначной трактовки культуры вообще, на основе которой могло бы даваться понятие экологической культуры. Целью данной статьи в этой связи будет являться уточнение составляющих понятия «экологическая культура» и формулировка его наиболее полного определения.

\section{ФУНКЦИИ КУАБТУРЫ}

В своем исследовании мы опираемся на позицию В. $\Lambda$. Бенина, который отмечает, что изучение любого культурного феномена требует выделения его функций. В философско-социальном смысле под функцией понимается роль, которую тот или иной социальный институт выполняет относительно потребностей общественной системы. Соответственно под функциями культуры, как пишет данный автор, подразумевается роль, которую она играет в жизни общества (Бенин и др., 2014: 76).

Так, В. $\Lambda$. Бенин в качестве главной выделяет человекотворческую функцию культуры. По мнению данного ученого, из нее вытекают остальные функции - знаковая, передачи социального опыта, регулятивная и ценностная. Знаковая функция основывается на том, что овладение культурой невозможно без овладения ее знаковыми системами. В свою очередь, культура может транслировать социальный опыт, только переводя его в специфические знаковые системы. Благодаря функции трансляции социального опыта каждое новое поколение получает как бы концентрированный опыт прошлого. Регулятивная функция предполагает определение норм, т. е. границ поведения, что способствует ограничению свобод человека. С ней тесно связана ценностная функция, которая направлена на формирование у человека определенных установок и ценностных ориентаций, опираясь на которые он принимает или отвергает увиденное, услышанное или познанное (там же: 77-78).

Интерес для исследования представляют работы таких известных ученых, как В. С. Библер (Библер, 1991), Э. В. Ильенков (Ильенков, 1991), М. С. Каган (Каган, 1988), $\Lambda$. Н. Коган (Коган, 1993), Э. В. Соколов (Соколов, 1972), которые наряду с перечисленными выше функциями культуры выделяют в качестве ее феноменологической характеристики диалоговую функцию.

\section{ФУНКЦИИ ЭКОАОГИЧЕСКОЙ КУАБТУРЫ}

Попытаемся раскрыть содержание определения экологической культуры, для того чтобы показать свою позицию по данному вопросу.

В качестве варианта рассмотрения дефиниций экологической культуры мы выбрали тот, который основывается на полноте представленности в них культурных функций. Проанализировав имеющиеся классификации относительно функционального состава понятия «экологическая культура» таких ученых, как С. В. Алексеев (Алексеев и др., 1996), В. А. Бенин (Бенин и др., 2014), А. Н. Коган (Коган, 1993), В. А. Ситаров, В. В. Пустовойтов (Ситаров, Пустовойтов, 2015) и др., мы выделили наиболее общие функции экологической культуры: ценностная, регулятивная, передачи социального опыта, диалоговая, знаковая. 
Также в данной статье проводится попытка разделить определения экологической культуры в зависимости от их принадлежности к тому или иному направлению научного исследования. Все определения мы будем подразделять на:

1) описательные, в которых авторы предпринимают попытки отразить все то, что охватывает понятие «экологическая культура»;

2) исторические, которые отражают исторические аспекты культурных феноменов, делают акцент на процессах социального наследования, традициях;

3 ) ценностные, включающие в себя идею образа жизни (представления об идеалах и ценностях);

4) психологические, в которых отражаются процессы адаптации к среде и процессы научения, формирования навыков, привычек, норм;

5) структурные, описывающие структурную организацию экологической культуры;

6) культурологические, рассматривающие экологическую культуру как компонент общей культуры.

7) комплексные - включающие в себя все вышеперечисленные подходы.

Рассмотрим конкретные определения по типам. Описательныле определения. Э. В. Гирусов понимает экологическую культуру как «совокупность материальных и духовных ценностей общества, а также способов деятельности, направленных на обеспечение сохранения природной среды» (Гирусов, 1989: 14). В данном случае отсутствуют знаковая и диалоговая функции. Кроме того, направленность содержания на сохранение только природной среды сужает его понятие, оставляя за пределами определения систему взаимоотношений «общество - природа - человек».

Исторические определения. В своей работе И. А. Сосунова и О. И. Марар предлагают следующее рабочее проблемно-ориентированное определение понятия. Экологическая культура, по их мнению, это «система исторически развивающихся надбиологических программ человеческой деятельности, распространяющихся на все сферы материальной и духовной жизни и направленных на регуляцию отношений общества и природы на основе принципа коэволюции» (Сосунова, Марар, 2009: 36). В данном случае отсутствует ценностная функция.

Ценностные определения. Так, О. А. Аагутин включает в структуру экологической культуры лишь духовные феномены, понимая экологическую культуру как «открытую, динамичную систему высоконравственных и ценностных установок, цель которой сохранение и развитие природно-социального потенциала человеческого общества, формирование “устойчивой” экологической сферы общества» (Аагутин, 2001: 14). В этом определении отсутствуют функции передачи социального опыта и регулятивная.

В. А. Ситаров и В. В. Пустовойтов определяют экологическую культуру как «нравственно-духовную сферу жизнедеятельности человека, характеризующую своеобразие его взаимодействия с природой и включающую в себя систему взаимосвязанных элементов: экологическое сознание, экологическое отношение и экологическую деятельность» (Ситаров, Пустовойтов, 2015: 156). Аанное определение достаточно полно передает смысл экологической культуры. Между тем нравственно-духовная сфера, на наш взгляд, должна распространяться не только на взаимоотношения с природой, но и с окружающей социальной и другими средами.

Психологические определения. Например, Е. И. Ефимова пишет: «Экологическая культура, как интегративное образование, характеризуется культурой познания и высоконравственного отношения к миру (естественной и искусственной среде): природе, технике, себе и другим людям; эти отношения воспринимаются, осознаются и ре- 
ализуются каждым человеком индивидуально, детерминируя его становление как личности через саморазвитие во взаимодействии с биосоциотехническими системами» (Ефимова, 2001: 21). Нам представляется, что это определение достаточно полно отражает смысл экологической культуры с психологической точки зрения.

С. В. Павлов, В. Н. Майстренко, Н. Г. Курамшина считают, что «экологическая культура - это усвоение основ современной экологии, природопользования и формирования на их базе экологического сознания, нравственных норм отношения к природе, которыми необходимо постоянно руководствоваться в повседневной жизни на работе, в быту, во взаимоотношениях с людьми» (Павлов, Майстренко, Курамшина, 1995: 149). Это определение экологической культуры представляется достаточно полным и законченным, включающим все необходимые функции. Можно лишь отметить, что категория «повседневная жизнь» включает в себя не только работу, быт и взаимоотношения с людьми, но и более широкие связи и отношения, характеризуемые в системе «природа - общество - человек».

Структурные определения. Экологическую культуру В. И. Залунин определяет как «уровень овладения человеком экологическими условиями своего бытия, экологическими знаниями, принципами и методами обеспечения устойчивого развития, гармонизации отношений между обществом и природой, облагораживания природы» (Залунин, 2005: 234-235). В определении отсутствует ценностная и регулятивная функции.

По мнению В. А. Игнатовой, «экологическая культура определяет характер и качественный уровень отношений между человеком и социоприродной средой и проявляется в системе духовных ценностей, во всех видах и результатах человеческой деятельности, связанных с познанием, использованием и научно обоснованным преобразованием природы» (Игнатова, 2005: 202). В данном случае отсутствуют знаковая функция и функция передачи социального опыта.

С. Н. Глазачев и О. Н. Козлова представляют экологическую культуру как «совокупность духовных ценностей, принципов правовых норм и потребностей, обеспечивающих оптимизацию взаимодействия общества и природы. Экологическая культура - становящийся социокультурный феномен, обладающий своей структурой, языками (наука, искусство, религия); специфическим пространством - временем» (Глазачев, Козлова, 1997: 43). В этом определении отсутствует лишь знаковая функция.

Культурологические определения. Экологическая культура трактуется А. С. Карповым как «неотъемлемая часть общечеловеческой культуры, включающая моральные ценности, нормы поведения, способы взаимодействия людей в сфере охраны окружающей среды и систему формирующих их социальных отношений, проявляющаяся в экологически ориентированном поведении людей, осознании общей ответственности за качество окружающей среды и высокой социальной значимости предотвращения негативного воздействия человека на окружающую среду» (Карпов, 2007: 12). Как нам представляется, это определение является достаточно полным и законченным, включающим все необходимые функции.

Некоторые авторы часто не выделяют различия в понимании сути экологической культуры как элемента культуры вообще. Например, Н. Ф. Реймерс в значительной мере отождествлял экологическую культуру и специфические особенности современной культуры в целом, рассматривая экологическую культуру как «этап и составную часть развития общемировой культуры, характеризуемые острым, глубоким и всеобщим осознанием насущной важности экологических проблем в жизни и будущем раз- 
вития человечества» (Реймерс, 1990: 259). Таким образом, раскрывается только знаковая функция.

Комплексный подход. Экологическую культуру как экологическую деятельность М. В. Рыбакова понимает в качестве комплексного понятия, которое охватывает различные «формы социальной деятельности, которые способствуют не только сохранению окружающей среды, но и социальному прогрессу, например, деятельность по рационализации потребностей социального субъекта, его экологическому образованию и воспитанию, образа жизни, формированию мышления и ответственного отношения к окружающему природному миру» (Рыбакова, 2006; цит. по: Томбу, 2007: 146). В данном случае отсутствует функция передачи социального опыта.

Так же широко понимает сферу проявления экологической культуры Е. В. Никонорова, которая определяет экологическую культуру как «специфически человеческую форму связи человека с природой, со всем окружающим его миром и мирозданием, самим собой и другими людьми» (Никонорова, 1994: 17). Не раскрыты регулятивная и ценностная функции.

Обобщая представленный обзор определений «экологическая культура» и ее составляющих, примем за основу ту формулировку, которую дал С. В. Алексеев, поскольку она в наибольшей степени отвечает логике нашего исследования: экологическая культура понимается «как система знаний, умений, ценностных ориентаций человека, верований, традиций, обычаев, законов, искусства, нравственности, ответственности за принимаемые решения и действия» (Алексеев, 1998: 13-14). Аанное определение является достаточно полным и законченным, включающим все выделенные функции экологической культуры. Также необходимо отметить, что автор раскрывает такую важную систему взаимоотношений, как «общество - природа человек».

\section{ЗАКАЮЧЕНИЕ}

Подводя итог вышесказанному, следует отметить, что общим признаком приведенного нами анализа дефиниций является наличие в них человека и его деятельности как смыслообразующего начала. Аанный анализ способствует более глубокому пониманию определений экологической культуры, а также наличия в них тех или иных составляющих.

Представленный функциональный состав экологической культуры позволяет рассматривать экологическую культуру как интегративное личностное качество, собственный вариант функционирования человека в социальной экокультурной системе, способ его гармонического, распространенного развития вследствие совокупности социальных качеств. В этом процессе экологическая культура стала системной, целостной и ценностно-направленной, способной к самоуправлению и саморегуляции и, соответственно, функционально обеспечивать высокую эффективность социально значимой экологической деятельности всех субъектов социума. Главным показателем уровня экологической культуры является то, насколько индивид или социальные группы способны осуществить этот идеал деятельности на практике, реализовать его в конкретных социальных условиях.

\section{СПИСОК АИТЕРАТУРЫ}

Алексеев, С. В. (1996) Практикум по экологии : учеб. пособие / С. В. Алексеев, Н. В. Груздева, А. Г. Муравьев, Э. В. Гущина ; общ. ред. С. В. Алексеева. М. : АО МАС. 192 с. 
Алексеев, С. В. (1998) Теоретические основы и методика экологической подготовки учителя в системе постдипломного образования : автореф. дис. ... А-ра пед. наук. СПб. 34 с.

Бенин, В. А. (2014) Культурологическая компетентность субъекта профессионально-педагогической деятельности : учеб. пособие для студентов и преподавателей высшей школы / В. А. Бенин, А. С. Василина, Е.А. Жукова. М. : Перо. 205 с.

Библер, В.С. (1991) От наукоучения - к логике культуры: два философских введения в двадцать первый век. М. : Политиздат. 413 с.

Гирусов, Э. В. (1989) Природные основы экологической культуры // Экология, культура, образование: Материалы к конф. / [Редкол.: Н. М. Мамедов (отв. ред.) и др.]. М. : Б. и. 242 с. С. 11-18.

Глазачев, С. Н., Козлова, О. Н. (1997) Экологическая культура : пробное учеб. пособие. М. : Горизонт. 208 с.

Ефимова, Е. И. (2001) Теория и практика становления экологической культуры будущего специалиста в условиях высшей школы : автореф. дис. ... А-ра пед. наук. Хабаровск. 44 с.

Залунин, В. И. (2005) Экологическая культура в контексте глобального экологического кризиса // Труды Аальневосточного государственного технического университета. № 139. C. $233-243$.

Игнатова, В. А. (2005) Концепции современного естествознания : учеб. пособие. Тюмень : Иза-во Тюменского гос. ун-та. 208 с.

Ильенков, Э. В. (1991) Философия и культура. М. : Политиздат. 464 с.

Каган, М. С. (1988) Мир общения: проблема межсубъектных отношений. М. : Политиздат. 319 c.

Коган, А. Н. (1993) Теория культуры. Екатеринбург : Изд-во Уральского гос. ун-та. 160 с.

Карпов, А. С. (2007) Концепция правового регулирования экологического образования // На пути к устойчивому развитию России : бюллетень. № 38: Экология и культура. С. 9-12.

Аагутин, А. О. (2001) Экологическая культура как фактор устойчивого развития общества : автореф. дис. ... канд. культурол. Краснодар. 19 с.

Никонорова, Е. В. (1994) Экологическая культура и факторы ее формирования: философско-социологический аспект проблемы : автореф. дис. ... А-ра филос. наук. М. 50 с.

Павлов, С. В., Майстренко, В. Н., Курамшина, Н. Г. (1995) Проблемы формирования экологической культуры // Экологическое образование. Перспективы и концепции инвайронментальной педагогики: Материалы конф., 29-30 ноября 1995 г. / Башк. ин-т повышения квалификации работников образования, Минприроды и ЧС РБ. Уфа. С. 146-152.

Ситаров, В. А., Пустовойтов, В. В. (2015) Социальная экология. М. : Юрайт. 517 с.

Соколов, Э. В. (1972) Культура и личность. $\Lambda$. : Наука. 228 с.

Сосунова, И. А., Марар, О. И. (2009) Экологическая культура: понятие, сущность, структура и функции // Поиск: Политика. Обществоведение. Искусство. Социология. Культура. № 1 (21). С. 29-40.

Реймерс, Н. Ф. (1990) Природопользование : словарь-справочник. М. : Мысль. 637, [2] с.

Рыбакова, М. В. (2006) Современная социальная экологическая практика. М. : Информ-Знание. $251 \mathrm{c}$.

Томбу, А. В. (2007) [Рец. на:] Рыбакова М. В. Современная социальная экологическая практика. М. : Информ-Знание, 2006. 251 с. // Социологические исследования. № 11. С. 146-147.

Аата поступления: 12.09.2015 2.

FUNCTIONS OF ENVIRONMENTAL CULTURE: ANALYZING THE DEFINITIONS

\section{A. A. Fortunatov}

(MOSCOW UNIVERSITY FOR THE HUMANITIES)

Recognizing the importance of building environmental culture and active engagement with the problem have not yet led to its theoretical and methodological comprehension. Researchers focus their attention on such urgent issues as the collapse of environmental culture followed by environ- 
mental pollution, exhaustion of resources and other consequences. These vitally important issues are often examined without relevant research methodology. Gradually there has emerged an understanding of the necessity of establishing a conceptual framework which would help study the formation of environmental culture.

Having analyzed a number of works by Russian researchers, we can conclude that environmental culture typically has the following functions: value-oriented, regulating, that of social experience transfer, dialogical and iconic. Also, the definitions of environmental culture have been classified into descriptive, historical, value-oriented, psychological, structural, and culturological. Under the specified criteria, we analyze the definitions of environmental culture according to the degree of representing cultural functions.

All of the definitions analyzed in the article share the human presence and activity as the most crucial feature, thus allowing to fully understand both the definitions of environmental culture and their components.

Keywords: functions of culture; environmental culture; functions of environmental culture

\section{REFERENCES}

Alekseev, S. V. (1996) Praktikum po ekologii [Workshop on ecology] : A textbook / S. V. Alekseev, N. V. Gruzdeva, A. G. Muraviev and E. V. Gushchina; ed. by S. V. Alekseev. Moscow, AO MDS Publ. 192 p. (In Russ.).

Alekseev, S. V. (1998) Teoreticheskie osnovy i metodika ekologicheskoi podgotovki uchitelia $v$ sisteme postdiplomnogo obrazovaniia [Theoretical foundations and methodology of environmental training of a teacher in of post-degree education] : Abstract of the diss. ... Doctor of Pedagogy. St. Petersburg. 34 p. (In Russ.).

Benin, V. L. (2014) Kul'turologicheskaia kompetentnost' sub' ekta professional' no-pedagogicheskoi deiatel'nosti [Culturological competence of the subject of professional and pedagogical activity] : A textbook for higher school students / V. L. Benin, D. S. Vasilina and E. D. Zhukova. Moscow, Pero Publ. 205 p. (In Russ.).

Bibler, V.S. (1991) Ot naukoucheniia - klogike kul'tury: Dva filosofskikb vvedeniia v dvadtsat' pervyi vek [From the doctrine of science to the logic of culture: Two philosophical introductions to the 21st century]. Moscow, Politizdat Publ. 413 p. (In Russ.).

Girusov, E. V. (1989) Prirodnye osnovy ekologicheskoi kul'tury [Natural foundations of environmental culture]. In: Ekologiia, kul'tura, obrazovanie [Ecology, culture, education] : Proceedings of the conference / ed. by N. M. Mamedov et al. Moscow, s.n. 242 p. Pp. 11-18. (In Russ.).

Glazachev, S. N. and Kozlova, O. N. (1997) Ekologicheskaia kul'tura [Environmental culture] : A pilot textbook. Moscow, Gorizont Publ. 208 p. (In Russ.).

Efimova, E. I. (2001) Teoriia i praktika stanovleniia ekologicheskoi kul'tury budushchego spetsialista $v$ usloviiakb vysshei shkoly [The theory and practice of building environmental culture in higher school] : abstract of the diss. ... Doctor of Pedagogy. Khabarovsk. 44 p. (In Russ.).

Zalunin, V. I. (2005) Ekologicheskaia kul'tura v kontekste global'nogo ekologicheskogo krizisa [Environmental culture in the context of global ecological crisis]. Trudy Dal' nevostochnogo gosudarstvennogo tekbnicheskogo universiteta, no. 139, pp. 233-243. (In Russ.).

Ignatova, V. A. (2005) Kontseptsii sovremennogo estestvoznaniia [Conceptions of modern natural sciences]: A textbook. Tyumen, Tyumen State University Publ. 208 p. (In Russ.).

Il'enkov, E. V. (1991) Filosofiia i kul'tura [Philosophy and culture]. Moscow, Politizdat Publ. 464 p. (In Russ.).

Kagan, M. S. (1988) Mir obshcheniia: problema mezhsub' ektnykb otnoshenii [The world of communication: The issue of intersubject relations]. Moscow, Politizdat Publ. 319 p. (In Russ.).

Kogan, L. N. (1993) Teoriia kul'tury [Theory of culture]. Ekaterinburg, Ural State University Publ. 160 p. (In Russ.).

Karpov, A. S. (2007) Kontseptsiia pravovogo regulirovaniia ekologicheskogo obrazovaniia [The conception of legal regulation of environmental education]. Na puti k ustoichivomu razvitiiu Rossii, no. 38: Ekologiia i kul’tura [Ecology and culture], pp. 9-12. (In Russ.). 
Lagutin, A. O. (2001) Ekologicheskaia kul'tura kak faktor ustoichivogo razvitiia obshchestva [Environmental culture as factor of society's sustainable development] : Abstract of the diss. ... Candidate of Culturology. Krasnodar. 19 p. (In Russ.).

Nikonorova, E. V. (1994) Ekologicheskaia kul' tura i faktory ee formirovaniia: filosofsko-sotsiologicheskii aspekt problemy [Environmental culture and the factors of its formation: Philosophical and sociological aspects]: Abstract of the diss. ... Doctor of Philosophy. Moscow. 50 p. (In Russ.).

Pavlov, S. V., Maistrenko, V. N. and Kuramshina, N. G. (1995) Problemy formirovaniia ekologicheskoi kul' tury [Problems of the formation of environmental culture]. In: Ekologicheskoe obrazovanie. Perspektivy i kontseptsii invaironmental' noi pedagogiki [Environmental education. Prospects and conceptions of environmental pedagogy] : Proceedings of a conference, November 29-30, 1995. Ufa. Pp. 146-152. (In Russ.).

Sitarov, V. A. and Pustovoitov, V. V. (2015) Sotsial'naia ekologiia [Social ecology]. Moscow, Iurait Publ. 517 p. (In Russ.).

Sokolov, E. V. (1972) Kul'tura i lichnost' [Culture and personality]. Leningrad, Nauka Publ. 228 p. (In Russ.).

Sosunova, I. A. and Marar, O. I. (2009) Ekologicheskaia kul'tura: poniatie, sushchnost', struktura i funktsii [Environmental culture: Concept, essence, structure and functions]. Poisk: Politika. Obshchestvovedenie. Iskusstvo. Sotsiologiia. Kul'tura, no. 1 (21), pp. 29-40. (In Russ.).

Reimers, N. F. (1990) Prirodopol'zovanie [Nature management]: Glossary. Moscow, Mysl' Publ. 637, [2] p. (In Russ.).

Rybakova, M. V. (2006) Sovremennaia sotsial'naia ekologicheskaia praktika [Contemporary social ecological practice]. Moscow, Inform-Znanie Publ. 251 p. (In Russ.).

Tombu, D. V. (2007) [Rets. na:] Rybakova M. V. Sovremennaia sotsial'naia ekologicheskaia praktika. M. : Inform-Znanie, 2006. 251 s. [Review: Rybakova M. V. Contemporary social ecological practice. Moscow, Inform-Znanie Publ., 2006. 251 p.]. Sotsiologicheskie issledovaniia, no. 11, pp. 146-147. (In Russ.).

Submission date: 12.09.2015.

Фортунатов Артем Александрович - кандидат педагогических наук, доцент кафедры педагогики и психологии высшей школы Московского гуманитарного университета. Адрес: 111395, Россия, г. Москва, ул. Юности, д. 5. Тел.: +7 (499) 374-74-59. Эл. адpec: art_fortunatov@mail.ru

SPIN-код РИНЦ: 4420-6517

Fortunatov Artem Aleksandrovich, Candidate of Pedagogy, Associate Professor, Department of Pedagogy and Psychology of Higher School, Moscow University for the Humanities. Postal address: 5 Yunosti St., 111395 Moscow, Russian Federation. Tel.: +7 (499) 374-74-59. E-mail: art_fortunatov@mail.ru 